\title{
Polyclonal intravenous immunoglobulin for the prophylaxis and treatment of infection in critically ill adults
}

\author{
Kevin B Laupland MD FRCPC
}

KB Laupland. Polyclonal intravenous immunoglobulin for the prophylaxis and treatment of infection in critically ill adults. Can J Infect Dis 2002;13(2):100-106.

Infection is a major cause of morbidity and mortality in critically ill patients. Despite advances in technology, its mortality rate has changed minimally over the past two decades, and new therapies are needed. Polyclonal intravenous immunoglobulin (IVIG) has been investigated both as a preventive and a treatment modality for sepsis and septic shock in critically ill adult patients. Prophylaxis with IVIG has been shown to reduce significantly the incidence of infection, particularly pneumonia, in selected postsurgical intensive care patients. However, it does not reduce mortality. The risk-benefit and cost effectiveness of this therapeutic intervention have not been determined, and its routine use is therefore not recommended. Treatment with IVIG has been shown in a number of small trials and a meta-analysis to reduce dramatically sepsis and septic shock mortality. However, a large, unpublished randomized trial has apparently shown no mortality benefit with this therapy. Despite limited evidence, IVIG has become the standard of care for the management of group A streptococcal toxic shock syndrome. At present, clinical equipoise exists for the use of IVIG in the treatment of sepsis and septic shock, and further study is needed.

Key Words: Critical care; Infection; Intensive care unit; Intravenous gamma globulin; Sepsis; Septic shock

\section{L'immunoglobuline intraveineuse polyclonale comme prophylaxie et traitement de l'infection chez des adultes en phase critique}

\begin{abstract}
RÉSUMÉ : L'infection est une cause importante de morbidité et de mortalité chez les patients en phase critique. Malgré les progrès de la technologie, le taux de mortalité a très peu changé depuis vingt ans, et de nouveaux traitements s'imposent. L'immunoglobuline intraveineuse polyclonale (IGIV) a été étudiée comme modalité de traitement à la fois préventive et en cas de septicémie et de choc septique chez des patients adultes en phase critique. Il est démontré que la prophylaxie à l'IGIV réduit l'incidence d'infection de manière appréciable, surtout pour ce qui est de la pneumonie chez des patients sélectionnés en soins intensifs après une opération. Cependant, cette prophylaxie ne réduit pas le taux de mortalité. Le rapport risques-avantages et le rapport coût-efficacité de cette intervention thérapeutique n'ont pas été établis; par conséquent, son utilisation systématique n'est pas recommandée. Selon plusieurs petits essais et méta-analyses, le traitement à l'IGIV réduit de façon significative le taux de mortalité secondaire à la septicémie et au choc septique. Cependant, un grand essai aléatoire non publié n'a apparemment démontré aucune diminution de la mortalité grâce à ce traitement. Malgré des observations limitées, l'IGIV est devenue la norme de soins dans la prise en charge du syndrome de choc toxique au streptocoque de groupe A. Pour l'instant, il existe une pondération clinique pour l'utilisation de l'IGIV dans le traitement de la septicémie et du choc toxique, et des études plus approfondies s'imposent.
\end{abstract}

Divisions of Infectious Disease and Critical Care, Department of Medicine, University of Calgary, Calgary, Alberta

Correspondence: Dr Kevin B Laupland, Divisions of Infectious Disease and Critical Care, Department of Medicine, University of Calgary,

Foothills Medical Centre, 3330 Hospital Drive NW, Calgary, Alberta T2N 4N1. Telephone 403-249-5675, fax 403-246-2219,

e-mail klauplan@ucalgary.ca

Received for publication October 11, 2001. Accepted October 16, 2001 
I nfection is a major cause of morbidity and mortality in 1 critically ill patients. Although Canadian incidence rates are unknown, it is estimated that 300,000 to 500,000 septic episodes occur each year in the United States, with a crude mortality rate of 35\% (1). Despite remarkable advances in medical and surgical care, the mortality rate from severe infections has declined only minimally over the past few decades (2). As a result, considerable effort has been devoted to developing new sepsis and septic shock therapies.

The dramatic clinical manifestations of sepsis and septic shock are believed to arise from an exaggerated immune response to Gram-negative lipopolysaccharide (LPS), or Gram-positive lipoteichoic acid or protein exotoxins. These bacterial antigens and superantigens induce the host production of proinflammatory cytokines, most importantly, interleukin-1-beta (IL-1 $\beta$ ) and tumour necrosis factoralpha (TNF- $\alpha$ ), which then lead directly and indirectly to the clinical manifestations of sepsis and septic shock $(3,4)$. New therapies have therefore targeted both bacterial components and the host-derived immune mediators in the management of sepsis and septic shock.

Large randomized clinical studies investigating the use of IL-1 $\beta$ receptor antagonists, soluble TNF- $\alpha$ receptors, and monoclonal anti-LPS and anti-IL-1 $\beta$ antibodies have not demonstrated any significant mortality benefit $(5,6)$. With the exception of one recent trial that enrolled highly selected patients, studies using anti-TNF- $\alpha$ antibody have also shown no mortality benefit (7). Alejandria et al (8) performed a meta-analysis of intravenous antibody therapies in sepsis and septic shock, and found no overall mortality benefit from monoclonal antiendotoxin $(n=1736)$ or anticytokine $(n=4318)$ products. There are a number of possible explanations for their apparent lack of efficacy. The timing of administration and dosing of these agents may not have been optimal. In addition, it may have been necessary to treat patients with therapies directed at both the inciting antigens and a number of different cytokines simultaneously rather than using monotherapy. This may be because the pathogenesis of sepsis and septic shock involves a complex interaction between the organism and a broad range of host mediators. Another possibility is that the agents studied were directed at the wrong targets or failed to address the importance of the interactions between the immune and coagulation systems in sepsis. The recent clinical trial showing that recombinant human activated protein $\mathrm{C}$ reduced mortality in patients with severe sepsis supports this argument (9). Because it has a broad range of known and unknown specificities and activities, intravenous immunoglobulin (IVIG) has been investigated as a preventive and therapeutic modality for infections in the critically ill. The present article reviews the rationale and evidence for the use of IVIG in the prophylaxis and treatment of infection in critically ill adult patients.

\section{WHAT IS IVIG?}

IVIG is polyclonal immunoglobulin that is derived from large pools of normal donor serum and prepared for intravenous injection. Intramuscular preparations of immune globulin first became available in the 1950s; IVIG became available in 1979 (10). Standard IVIG contains primarily immunoglobulin $\mathrm{G}$ from as many as 30,000 plasma donors $(11,12)$. As a result of pooling, IVIG reflects the prevalent immunity of the plasma donor population and, therefore, antibody titres and specificities vary among different lots and manufacturers (13). Different preparations have in common a broad range of antibodies to microorganisms and their extracellular products, cytokines, and contain soluble human leukocyte antigens class I and II (14).

Therapeutic IVIG is generally well tolerated and has a good safety profile. A $2 \mathrm{~g} / \mathrm{kg}$ dose will increase serum levels by 2 to $3 \mathrm{~g} / \mathrm{L}$ (normal range 6 to $16 \mathrm{~g} / \mathrm{L}$ ), with a return to baseline at 23 to 28 days (10). There are anecdotal reports of acute tubular necrosis, aseptic meningitis, central retinal vein obstruction, myocardial infarction and deep venous thrombosis associated with IVIG use. However, large randomized trials investigating IVIG use in patients with a wide range of medical conditions have shown a low incidence of adverse events that is comparable with use of a placebo $(12,15-17)$. Because it is a concentrated colloid solution, high doses of IVIG may precipitate congestive heart failure or exacerbate volume overloaded states. Patients with selective immunoglobulin A deficiency may have a severe anaphylactic reaction to IVIG, and it is contraindicated in these patients. Compared with other blood and plasma products, the risk of transmitting infectious agents with IVIG is believed to be negligible. This is because, in addition to careful screening of donors and rigorous quality control, the purification process is toxic to viruses and bacteria. The process varies among manufacturers, but is usually based on the cold ethanol fractionation method of Cohn and Oncley $(13,18)$. Additional processing is then performed to remove aggregates and anticomplement proteins. Techniques may include enzymatic cleavage, chemical modification and nonmodified purification procedures, including polyethyleneglycol/hydroxyethyl starch precipitation, lyophilization, diafiltration, ultrafiltration, ion exchange, and exposure to acid, heat or detergents $(13,18)$. Despite these precautions, there is always the potential risk of transmitting infectious agents that have yet to be discovered.

IVIG has been used therapeutically in a broad range of infectious and noninfectious disorders. However, it is expensive, with an approximate cost of $\$ 40 / \mathrm{g}$, the evidence for its use in many indications is weak, and there is an ever present risk of shortages because Canada imports more than one-half of its IVIG supply (19). Because of these concerns, a Canadian consensus group was formed to explore indications for IVIG use. They conducted a survey among Canadian specialists who reported a total of 142 potential uses for IVIG (10). The investigators then performed an extensive review of the literature to determine evidencebased indications for IVIG use. However, with the exception of streptococcal toxic shock syndrome, they did not present the evidence for IVIG as a preventive or treatment modality for sepsis and septic shock in adults. 
TABLE 1

Randomized, controlled trials of intravenous immunoglobulin (IVIG) for the prophylaxis of infection in critically ill adults

\begin{tabular}{|c|c|c|c|c|c|}
\hline Setting & Design (doses used) & Patients (n) & Main outcomes & Limitations & Reference \\
\hline Surgical ICUs & $\begin{array}{l}\text { RDBPCT (standard IVIG } \\
400 \mathrm{mg} / \mathrm{kg} \text {, hyperimmune } \\
\text { LPS IVIG } 400 \mathrm{mg} / \mathrm{kg} \text { or } \\
25 \% \text { albumin) }\end{array}$ & 329 & $\begin{array}{l}\text { Infection incidence with standard IVIG } \\
33 \% \text { versus placebo } 47 \%, P=0.03 \text {; } \\
\text { fewer pneumonias, shorter ICU stay } \\
\text { with IVIG compared with placebo }\end{array}$ & $\begin{array}{l}\text { Analysis, not intention- } \\
\text { to-treat, but unlikely to } \\
\text { change results }\end{array}$ & 11 \\
\hline $\begin{array}{l}\text { Trauma patients } \\
\text { in ICU ventilated } \\
>24 \mathrm{~h}\end{array}$ & $\begin{array}{l}\text { RDBPCT ( } 36 \mathrm{~g} \mathrm{IVIG} \text { versus } \\
0.03 \% \text { albumin) }\end{array}$ & 150 & $\begin{array}{l}\text { Decreased overall incidence of infection } \\
47 \% \text { versus } 68 \%, P=0.02 \text {; decreased } \\
\text { antibiotics in IVIG group }\end{array}$ & $\begin{array}{l}\text { Blinding process not } \\
\text { well described }\end{array}$ & 12 \\
\hline $\begin{array}{l}\text { Postoperative } \\
\text { open heart } \\
\text { surgery patients } \\
\text { with cutaneous } \\
\text { anergy } \\
\text { preoperatively }\end{array}$ & $\begin{array}{l}\text { RDBPCT ( } 20 \mathrm{~g} \text { IgA- and } \\
\text { IgM-enriched IVIG versus } \\
\text { saline) }\end{array}$ & 40 & $\begin{array}{l}\text { Infection incidence } 5 \% \text { IVIG versus } \\
43 \% \text { placebo, } P=0.007\end{array}$ & $\begin{array}{l}\text { Highly selected patients } \\
\text { (40 of } 515)\end{array}$ & 20 \\
\hline $\begin{array}{l}\text { Trauma patients } \\
\text { in ICU with } \\
\text { injury severity } \\
\text { score } 16 \text { to } 50\end{array}$ & $\begin{array}{l}\text { RDBPCT ( } 1 \mathrm{~g} / \mathrm{kg} \text { IVIG } \\
\text { versus } 1 \mathrm{~g} / \mathrm{kg} \text { albumin) }\end{array}$ & 39 & $\begin{array}{l}\text { No difference in overall infection rates, } \\
\text { but fewer pneumonias and noncatheter- } \\
\text { related infections; no difference in } \\
\text { ICU length of stay or antibiotic use }\end{array}$ & $\begin{array}{l}\text { Small numbers may not } \\
\text { detect significant differences } \\
\text { highly selected patients } \\
\text { (39 of 196) }\end{array}$ & 21 \\
\hline $\begin{array}{l}\text { Major surgery } \\
\text { and trauma } \\
\text { ICU patients }\end{array}$ & $\begin{array}{l}\text { RDBPCT ( } 40 \mathrm{~g} \text { IVIG versus } \\
5 \% \text { dextrose) }\end{array}$ & 40 & $\begin{array}{l}\text { No difference in rates of sepsis or } \\
\text { mortality; less positive blood } \\
\text { cultures in IVIG group in the second } \\
\text { week of observation }\end{array}$ & $\begin{array}{l}\text { Small numbers may not } \\
\text { detect significant differences } \\
\text { incidence of nonseptic } \\
\text { infections not reported }\end{array}$ & 23 \\
\hline
\end{tabular}

ICU Intensive care unit; Ig Immunoglobulin; LPS Lipopolysaccharide; RDBPCT Randomized, double-blinded, placebo controlled trial

\section{EVIDENCE FOR IVIG AS PROPHYLACTIC THERAPY}

Randomized clinical trials investigating the use of IVIG as a prophylactic agent in critically ill patients were initially identified by searching MEDLINE from 1966 to December 2000. Search terms were immunoglobulins, intravenous immunoglobulins, passive immunization, or immunoglobulin $G$ and infection, sepsis, sepsis syndrome or septic shock. Studies included were limited to those that enrolled patients older than 12 years, and human and clinical trials. Abstracts were then screened to identify prospective clinical trials in critically ill patients that compared an IVIG therapy group with a control group. Full-length reports were then retrieved, and further studies were searched for using the bibliographies of these reports and review articles. Five prospective clinical trials that focused on the use of IVIG as a preventive therapy for infection in intensive care unit (ICU) patients were identified for critical appraisal (Table 1).

The best quality evidence for the efficacy of IVIG in the prophylaxis of infection has been reported by The Intravenous Immunoglobulin Collaborative Study Group (11). This randomized, double-blind, placebo controlled trial conducted in surgical ICUs in Belgium, Switzerland and the United States randomly assigned 352 patients (329 evaluated) to treatment with standard IVIG, LPS hyperimmune IVIG or $25 \%$ albumin placebo. They observed a lower rate of overall infection in the standard IVIG group of 36 of 109 patients (33\%) compared with 53 of 112 placebo patients $(47 \%, \mathrm{P}=0.03)$. Patients treated with standard IVIG compared with placebo also had lower rates of pneumonia ( $14 \%$ versus $27 \%$, respectively, $\mathrm{P}=0.04)$ and a short- er median length of stay in the ICU (four versus six days, respectively, $\mathrm{P}=0.02$ ). There was no significant difference among the groups with respect to the incidence of septic shock or mortality rate. Hyperimmune LPS IVIG was similar to placebo for all comparisons.

Glinz et al (12) from Zurich, Switzerland reported a randomized, double-blind, placebo controlled trial of 150 trauma patients mechanically ventilated for longer than $24 \mathrm{~h}$. Seventy-six patients were allocated to $36 \mathrm{~g}$ of IVIG, and 74 patients were allocated to $0.03 \%$ albumin. The number of infections (over 42 days) was 36 in the IVIG group $(47 \%)$ versus 50 in the control group $(68 \%, \mathrm{P}=0.02)$, with most of the difference secondary to a lower incidence of pneumonia in the IVIG group compared with the control group at 28 patients $(37 \%)$ versus 43 patients $(58 \%$, $\mathrm{P}=0.001$ ), respectively. No statistically significant differences were observed in the mortality rate of 23 patients (30\%) versus 15 patients (20\%), respectively, but IVIG use was associated with fewer antibiotic days compared with the control group (1120 versus 1641 days, respectively).

Kress et al (20) conducted a randomized, double-blind, placebo controlled trial in Wurzburg, Germany with anergic postoperative open heart surgery patients. They preoperatively tested the cutaneous delayed-type hypersensitivity responses of 515 patients to seven common antigens and identified 44 patients with anergy. These patients were then randomly assigned to either $20 \mathrm{~g}$ IVIG (immunoglobulin A- and immunoglobulin $\mathrm{M}$-enriched) or saline and assessed prospectively for the development of infection postoperatively. Of 40 evaluated patients, one patient $(5 \%)$ in the IVIG group developed an infection 
TABLE 2 Randomized trials of intravenous immunoglobulin (IVIG) for the treatment of sepsis and septic shock in the
intensive care unit (ICU)

\begin{tabular}{|c|c|c|c|c|c|}
\hline Setting & Design & Patients (n) & Main outcomes & Limitations & Zeference \\
\hline $\begin{array}{l}\text { Surgical and trauma } \\
\text { ICU patients with } \\
\text { sepsis scores }>20\end{array}$ & $\begin{array}{l}\text { RDBPCT (1 g/kg IVIG } \\
\text { versus albumin) }\end{array}$ & 62 & $\begin{array}{c}\text { Reduced mortality of } 33 \% \text { IVIG } \\
\text { versus } 67 \% \text { placebo, } P<0.05\end{array}$ & $\begin{array}{l}\text { Highly selected surgical } \\
\text { patients }\end{array}$ & 24 \\
\hline $\begin{array}{l}\text { Surgical and trauma } \\
\text { ICU patients with } \\
\text { sepsis scores } \geq 17\end{array}$ & $\begin{array}{l}\text { RDBPCT (1 g/kg IVIG } \\
\text { versus albumin) }\end{array}$ & $\begin{array}{l}51 \text { (excluding } \\
\text { those pooled from } \\
\text { prior study [24]) }\end{array}$ & $\begin{array}{l}\text { Reduced mortality of } 29 \% \text { IVIG } \\
\text { versus } 61 \% \text { placebo, } P=0.021\end{array}$ & $\begin{array}{l}\text { Highly selected surgical } \\
\text { patients }\end{array}$ & 27 \\
\hline $\begin{array}{l}\text { ICU patients with } \\
\text { Gram-negative } \\
\text { septic shock }\end{array}$ & $\begin{array}{l}\text { Open-label, randomized } \\
\text { trial ( } 60 \mathrm{~g} \text { IVIG versus } \\
\text { ‘usual care') }\end{array}$ & 55 & $\begin{array}{l}\text { Reduced septic mortality of } \\
4 \% \text { IVIG versus } 32 \% \text { control, } \\
P<0.01\end{array}$ & $\begin{array}{l}\text { Highly selected patients } \\
\text { (69 of } 860) \text {, multiple interim } \\
\text { analyses, unblinded }\end{array}$ & 28 \\
\hline $\begin{array}{l}\text { ICU patients with } \\
\text { clinical sepsis } \\
\text { and endotoxemia }\end{array}$ & $\begin{array}{l}\text { Randomized, controlled tria } \\
\text { (IVIG } 0.5 \mathrm{~g} / \mathrm{kg} \text { versus } \\
\text { control) }\end{array}$ & rial & $\begin{array}{l}\text { Nonsignificant decrease in } \\
\text { mortality of } 63 \% \text { IVIG versus } \\
86 \% \text { control, } P=\text { not significant }\end{array}$ & $\begin{array}{l}\text { Unclear if adequate blinding, } \\
\text { intervention late in illness, } \\
\text { small sample size, low } \\
\text { dose IVIG }\end{array}$ & 30 \\
\hline $\begin{array}{l}\text { Postoperative patients } \\
\text { with sepsis }\end{array}$ & $\begin{array}{l}\text { Open-label, randomized tri } \\
\text { (IVIG dose not stated) }\end{array}$ & rial & $\begin{array}{l}\text { Mortality rate } 44 \% \text { IVIG versus } \\
76 \% \text { control, } P=\text { not significant }\end{array}$ & Unblinded, small sample size & 31 \\
\hline $\begin{array}{l}\text { Septic medical and } \\
\text { surgical ICU } \\
\text { patients }\end{array}$ & $\begin{array}{l}\text { Open-label, randomized tri } \\
\text { ( } 1 \mathrm{~g} / \mathrm{kg} \text { IVIG versus ‘usua } \\
\text { care’) }\end{array}$ & $\begin{array}{l}\text { rial } \\
\text { ral }\end{array}$ & $\begin{array}{l}\text { No significant difference in } \\
\text { mortality ( } 58 \% \text { IVIG versus } \\
75 \% \text { control) }\end{array}$ & $\begin{array}{l}\text { Grossly underpowered, } \\
\text { unblinded }\end{array}$ & 32 \\
\hline $\begin{array}{l}\text { ICU patients at first } \\
\text { sign of infection }\end{array}$ & $\begin{array}{l}\text { IVIG (dose not stated) } \\
\text { versus 'usual care' }\end{array}$ & $\begin{array}{c}104 \text { (only } 14 \\
\text { with sepsis } \\
\text { or septic shock) }\end{array}$ & No difference in mortality & $\begin{array}{l}\text { Unblinded, small number of } \\
\text { patients with sepsis or } \\
\text { septic shock }\end{array}$ & 33 \\
\hline $\begin{array}{l}\text { Septic medical and } \\
\text { surgical ICU } \\
\text { patients }\end{array}$ & $\begin{array}{l}\text { Multicentred, RDBPCT } \\
(0.9 \mathrm{~g} / \mathrm{kg} \text { IVIG versus } \\
\text { albumin })\end{array}$ & 653 & $\begin{array}{l}\text { No difference in mortality, but } \\
\text { actual rates not reported }\end{array}$ & $\begin{array}{l}\text { Unpublished despite } \\
\text { completion four years ago, } \\
\text { enrolment appears to have } \\
\text { ended prematurely }\end{array}$ & 34 \\
\hline
\end{tabular}

RDBPCT Randomized, double-blind, placebo controlled trial

compared with nine patients (43\%) in the placebo group $(\mathrm{P}=0.007)$. No significant differences were observed with respect to mortality rate, or ICU or hospital length of stay, although the study was underpowered to determine clinically significant differences.

In a randomized, double-blind, placebo controlled trial by Douzinas et al (21) from Athens, Greece, 39 multitrauma patients were selected from 196 screened patients and were randomly assigned within $12 \mathrm{~h}$ of ICU admission to $1 \mathrm{~g} / \mathrm{kg}$ of IVIG or human albumin divided over four days. Baseline characteristics were similar in the two groups, except that the IVIG group had higher injury severity scores (22). After controlling for injury severity scores, no overall difference in infection incidence was observed, but pneumonia $(\mathrm{P}=0.003)$ and noncatheter-related infections $(P=0.04)$ were reduced with IVIG compared with the control group. Catheter-related infections, antibiotic use, mortality and ICU length of stay did not significantly differ between the groups. Limitations of this study included the small sample size and failure to use an intention-to-treat analysis. They excluded three patients in the control group from analysis for protocol violations (two of which had infections) that may potentially bias for no difference.

Mao and colleagues (23) from Torino, Italy conducted a randomized, double-blind, placebo controlled trial among 40 surgical ICU patients. They randomly assigned postoperative major surgery and trauma patients to $40 \mathrm{~g}$ IVIG or $5 \%$ dextrose. Five IVIG-treated and three control patients died within $48 \mathrm{~h}$ of random assignment and were excluded from analysis. Three IVIG-treated patients developed sepsis compared with six control patients $(\mathrm{P}>0.05)$. Although there was no difference in the development of positive blood cultures during the first week of observation, in the second week, no patients treated with IVIG had positive blood cultures compared with six patients in the placebo group $(\mathrm{P}<0.05)$. The authors did not report the incidence of other infectious syndromes. There was a nonsignificant difference in mortality among patients treated with IVIG (two of $15,13 \%$ ) versus placebo (four of $17,24 \%$ ). This study was limited by its small sample size and failure to report the incidence of nonseptic infectious complications.

\section{EVIDENCE FOR IVIG AS ADJUVANT THERAPY}

Polyclonal IVIG has been investigated as an adjunctive treatment modality in sepsis and septic shock. Randomized clinical trials of IVIG in the treatment of sepsis and septic shock were searched using the strategy described for prophylaxis in the preceding section. Eight articles were identified that fulfilled the criteria of prospective, controlled studies of IVIG treatment focusing on critically ill adults with sepsis and septic shock (Table 2). 
The best evidence for efficacy of IVIG in the treatment of sepsis and septic shock comes from an Italian trial by Dominioni et al (24). In this multicentred, randomized, double-blind, placebo controlled trial, they enrolled 62 consecutive surgical and trauma patients with sepsis scores higher than 20 (mean Apache II score 18) and randomly assigned them to either $1 \mathrm{~g} / \mathrm{kg}$ of IVIG or albumin administered over a five-day period $(25,26)$. They observed a 28-day mortality rate of 11 of 29 IVIG-treated patients (38\%) compared with 22 of 33 control patients $(67 \%$, $\mathrm{P}<0.05)$. The decrease in mortality was related to a decrease in sepsis-related mortality in the IVIG group compared with the control group ( $7 \%$ versus $33 \%$, respectively, $\mathrm{P}<0.05)$. A trend for a decrease in positive blood cultures after randomization was observed among IVIG patients, suggesting that this therapy may increase the clearance of microorganisms from the blood (five of 29 IVIG-treated patients versus 12 of 33 control patients, $\mathrm{P}>0.05$ ).

Dominioni and colleagues (27) subsequently completed a second randomized trial similar to the first, with the exception that they included patients with sepsis scores of 17 or higher. They reported the results pooled with their initial trial and observed a lower overall mortality rate of 19 of 57 IVIG-treated patients (33\%) compared with 36 of 56 control patients $(64 \%, \mathrm{P}<0.005)(24,27)$. The decrease in mortality was due primarily to a reduction in mortality among patients with intermediate sepsis scores of 20 to 25 (11 of 33 IVIG-treated patients [33\%] versus 23 of 35 control patients [66\%], $\mathrm{P}<0.025)$. No statistically significant differences were observed in mortality reductions with IVIG among patients with sepsis scores of 17 to 19 (none of 10 IVIG-treated patients versus two of seven control patients) and higher than 25 (eight of 14 IVIG-treated patients versus 11 of 14 control patients). An important finding of this trial was that a consistently lower mortality rate was observed with IVIG therapy in the second group of independently studied patients. If the patients in the first published trial by Dominioni and colleagues (24) are excluded from the analysis, the mortality rate among the 51 patients in the second study (27) is again statistically significant - eight of 28 IVIG-treated patients (29\%) compared with 14 of 23 control patients (61\%, P=0.021, Fisher's exact test).

Schedel et al (28) reported an open-label, prospective, randomized, controlled trial of 55 patients with Gram-negative septic shock (medical and surgical) as identified by the limulus amebocyte lysate assay. They randomly assigned patients to $60 \mathrm{~g}$ IVIG or 'usual care'. They observed a septic mortality rate of one of 27 IVIG-treated patients (4\%) compared with nine of 28 control patients (32\%) within six weeks of randomization $(\mathrm{P}<0.01)$. Furthermore, they observed a faster decrease in endotoxin in blood (24 h) in IVIG-treated patients compared with control patients (four days, $\mathrm{P}<0.01$ ). This study was limited because patient allocation was not blinded, and because endotoxemia was an enrolment criterion, the results can only be generalized to patients with Gram-negative sepsis. Furthermore, this study has been criticized both in methodology and in conduct, because the authors performed multiple interim analyses, reported septic rather than all-cause mortality rate and may have modified the inclusion criteria after the start of the trial (29).

Grundmann and Hornung (30) from Koln, Germany reported on a randomized, controlled trial of IVIG $(0.5 \mathrm{~g} / \mathrm{kg})$ therapy among $46 \mathrm{ICU}$ patients with clinical sepsis and endotoxemia. They observed a nonsignificant lower mortality rate of 15 of 24 IVIG-treated patients (63\%) compared with 19 of 22 control patients (86\%). An important limitation is that they treated patients at least $48 \mathrm{~h}$ after presentation (average six days after ICU admission). This may potentially bias for no effect for IVIG, because if this treatment is useful, it is expected to have its greatest effect if given early in the disease course, when the cytokine cascade is initiated. The small study sample size and the use of a relatively low dose of IVIG may further bias the results toward no effect. Finally, the study methodology did not define whether there was adequate blinding, which could potentially bias the result in favour of or against IVIG efficacy.

This same group of investigators also reported, in the German literature, a single centre, open-label, randomized clinical trial (31). They randomly assigned 35 postoperative ICU patients with sepsis scores of 12 or higher to treatment with IVIG (total gram dose not specified) or control. There was no statistically significant reduction in mortality among patients treated with IVIG (eight of 18, 44\%) compared with control (13 of 17, 76\%). They also observed a nonstatistically different lower ICU stay (13 days versus 16 days) and ventilator days ( 10 days versus 13 days). The main limitations of this study relate to its small sample size and that the investigators were not blinded to the type of treatment received.

De Simone et al (32) reported a randomized, open-label clinical trial of IVIG $1.0 \mathrm{~g} / \mathrm{kg}$ versus 'usual care' in 24 septic ICU patients (16 surgical) from Rome, Italy. They found a statistically nonsignificant mortality reduction in patients undergoing IVIG treatment compared with control patients (seven of 12 patients [58\%] versus nine of 12 patients [75\%], respectively). However, the study was grossly underpowered to detect a clinically significant mortality reduction. A trend was observed for an increased median survival of 30 days versus 10 days in the IVIG and control groups, respectively $(\mathrm{P}<0.1)$. Of interest, the percentage of days of ICU stay on antibiotics was less in the IVIG group compared with the control group (38\% versus $95 \%, \mathrm{P}<0.01)$. A conclusion regarding an antibiotic-sparing effect of IVIG cannot be made because the study was not blinded, and knowledge of treatment with IVIG may have influenced the decision to discontinue treatment with antibiotics.

Just and colleagues (33) reported, in the German literature, an open-label, randomized, controlled trial in 104 ICU patients. They randomly assigned patients at first sign of infection to treatment with IVIG (total gram dose not stated) or usual care. There was no significant difference in mortality among patients treated with IVIG (25 of 50, 
$50 \%$ ) compared with control patients ( 22 of $54,41 \%$ ). No significant differences in overall length of stay or number of days of mechanical ventilation were observed. The most important limitation of this study is that patients tended to have mild infection-related illness, because only six patients treated with IVIG and eight control patients had criteria for either sepsis or septic shock (8). Thus, the severity of illness of the majority of the patients in this study was not related to infection, and IVIG would not be expected to modify significantly their disease course.

Overall, the published clinical trials suggest a beneficial mortality effect for treatment with IVIG in selected patients with sepsis and septic shock. Alejandra et al (8) have performed a meta-analysis based on five trials $(24,28,30-32)$. These authors calculated an overall dramatic reduction in mortality among adult patients treated with IVIG compared with control patients $(\mathrm{n}=222, \mathrm{RR}=0.60$, 95\% CI 0.47 to 0.77 ) (8). However, these results must be interpreted carefully, because each of the individual studies were relatively small, had highly selected patients, and were of variable quality in both methodology and conduct, as detailed in the preceding paragraphs.

Werdan and colleagues recognized the importance of a large, randomized trial to further define the role of IVIG in septic shock and completed a trial with 653 septic patients (34-36). In their multicentred, randomized, double-blind, placebo controlled trial, they enrolled medical and surgical patients with sepsis scores of 12 to 27 and Apache II scores of 20 to 35 (35). Patients were randomly assigned to $0.9 \mathrm{~g} / \mathrm{kg}$ IVIG versus albumin placebo. This study was apparently completed in 1996, but it has not been published as a full manuscript (36). In a review article on immunoglobulin use in sepsis, the authors reported that their study showed no 28 day mortality difference, but they did not give the actual mortality rates (34). However, they did observe a statistically significant decrease in both the Apache II and sepsis scores from day 0 to day 4 (34). At present, this study cannot be adequately appraised, because it has not been published in a peer reviewed journal. One concern is that the study may have been ended prematurely because only 653 patients were enrolled, despite publishing an a priori sample size calculation of 800 patients (35).

\section{SUMMARY}

Prospective, randomized, placebo controlled clinical trials have consistently demonstrated lower incidence rates of infection, particularly pneumonia, among critically ill postsurgical patients receiving prophylaxis with IVIG. However, these studies have not shown any significant decrease in mortality, and have had variable reductions in antimicrobial use and length of ICU stay associated with IVIG therapy. Furthermore, the risk-benefit and cost effectiveness of IVIG in this setting have not been determined, and because the studies have tended to include highly selected patients, generalization beyond the study populations is difficult. Despite good evidence that IVIG reduces the incidence of infection in highly selected, critically ill postsurgical patients, its use cannot be recommended at the current time, because it has not been shown to be superior to the standard practice of antibiotic treatment of infection once it occurs. However, if the rate of infection with multidrug-resistant organisms among critically ill patients continues to rise, IVIG prophylaxis may play an increasingly important role in the management of these patients.

IVIG is a promising adjunctive treatment modality for sepsis and septic shock, but randomized trial evidence is conflicting. Small, randomized trials have shown improvement in mortality with IVIG use, and an overall significant reduction has been identified using meta-analysis. However, a generally well-designed, large, randomized trial has apparently shown no mortality benefit. It is therefore unclear whether there is a significant mortality benefit associated with the use of IVIG in sepsis and septic shock. The small trials and meta-analysis may potentially be overestimating the usefulness of IVIG, in part because of biased study designs or conduct and possibly from publication bias of trials that demonstrate significantly different results. However, the magnitude of the risk reduction observed in the best of the small studies and the meta-analysis does raise the possibility of a significant effect with IVIG treatment. On the other hand, a large, well-designed trial has shown no mortality difference, but it remains unpublished and may have been ended prematurely. At present, clinical equipoise exists for the use of IVIG in sepsis and septic shock, and further evaluation is warranted. Because of its high cost, IVIG is not currently recommended as a routine adjunctive therapy in the treatment of sepsis and septic shock.

There are a number of issues that need to be addressed in any future clinical trials of IVIG in the treatment of sepsis and septic shock. The available evidence suggests that patients with intermediate degrees of severity of septic shock appear to have the greatest benefit, and these patients should comprise the study populations. The timing and dose of IVIG also need to be optimized. Early treatment is expected to have the greatest impact by minimizing the cascade of proinflammatory cytokines. Furthermore, clinical trials, so far, have used a maximum dose of $1 \mathrm{~g} / \mathrm{kg}$ IVIG that is typically given in divided doses over several days, and this may be inadequate. Based on experience with illnesses in which IVIG therapy has been proven effective, such as Kawasaki disease, a single $2 \mathrm{~g} / \mathrm{kg}$ dose may be more appropriate (37). Another important consideration is that mortality may not be the best outcome measure. Organ failure and quality of life have been suggested as being more valid (38). Finally, IVIG trials should not continue to be restricted to Gram-negative infections, because this treatment particularly may be of benefit in toxigenic, Gram-positive infections. Kaul et al (39) performed a case-comparative study with group A streptococcal toxic shock syndrome patients and found a significant mortality difference of $34 \%$ of 21 cases treated with IVIG compared with $67 \%$ of 32 historical controls $(\mathrm{P}=0.02)$. However, these results must be interpreted with caution, because the control patients were historical, and IVIG patients were 
more likely to be treated with surgery and receive clindamycin, which may bias toward better outcomes.

\section{CONCLUSIONS}

IVIG use does prevent infection in highly selected surgical patients, but its routine use is not recommended based on a lack of documented cost effectiveness and risk-benefit. There is conflicting evidence for a mortality benefit for IVIG as a treatment adjunct for sepsis and septic shock, and further study is needed. Because of its high cost, it is not currently recommended as routine therapy. Despite a lack of good clinical trial evidence, IVIG has become a standard of care and is recommended for the treatment of streptococcal toxic shock syndrome.

ACKNOWLEDGEMENTS: Dr Laupland was supported by the 2000 Bayer Healthcare/Canadian Institutes of Health Research/Canadian Infectious Diseases Society Infectious Diseases Research Fellowship and was the recipient of a clinical fellowship award from the Alberta Heritage Foundation for Medical Research. Dr Laupland thanks Dr Andreas Kramer for translating the German articles, and Drs Brenda R Laupland and H Dele Davies for their critical review of the manuscript.

\section{REFERENCES}

1. Balk R. Severe sepsis and septic shock. Definitions, epidemiology, and clinical manifestations. Crit Care Clin 2000;16:179-92.

2. Friedman G, Silva E, Vincent J-L. Has the mortality of septic shock changed with time? Crit Care Med 1998;26:2078-86.

3. Lynn W, Cohen J. Adjunctive therapy for septic shock: A review of experimental approaches. Clin Infect Dis 1995;20:143-58.

4. Marrack P, Kappler J. The staphylococcal enterotoxins and their relatives. Science 1990;248:705-11.

5. Dinarello C. Proinflammatory and anti-inflammatory cytokines as mediators in the pathogenesis of septic shock. Chest 1997;112(Suppl 6):321S-9S.

6. Vincent J. New therapies in sepsis. Chest 1997;112(Suppl 6):330S-8S.

7. Zygun D, Anderson I, Kramer A, Laupland K, Doig C,

Winston B. Critical care update in the new millenium.

Ann R Coll Physicians Surg Can 2001;34:297-301.

8. Alejandria M, Lansang M, Dars L, Mantaring J. Intravenous immunoglobulin for treating sepsis and septic shock. Cochrane Database Syst Rev 2000;(2):CD001090.

9. Bernard G, Vincent J-L, Laterre P, et al. Efficacy and safety of recombinant human activated protein $\mathrm{C}$ for severe sepsis. N Engl J Med 2001;344:699-709.

10. The Consensus Working Group. Present and future uses of IVIG: A Canadian multidisciplinary consensus-building initiative. Can J Allergy Clin Immunol 1997;2:176-207.

11. The Intravenous Immunoglobulin Collaborative Study Group. Prophylactic intravenous administration of standard immune globulin as compared with core-lipopolysaccharide immune globulin in patients at high risk of postsurgical infection. N Engl J Med 1992;327:234-40.

12. Glinz W, Grob P, Nydegger U, et al. Polyvalent immunoglobulins for prophylaxis of bacterial infections in patients following multiple trauma. A randomized, placebo-controlled study. Intensive Care Med 1985;11:288-94.

13. Greenbaum B. Differences in immunoglobulin preparations for intravenous use: A comparison of six products. Am J Pediatr Hematol Oncol 1990;12:490-6.

14. Ross C, Svenson M, Nielsen H, Lundsgaard C, Hansen M, Bendtzen K. Increased in vivo antibody activity against interferon $\alpha$, interleukin-1 $\alpha$, and interleukin- 6 after high dose Ig therapy. Blood 1997;90:2376-80.

15. Fazekas F, Deisenhammer F, Strasser-Fuchs S, Nahler G, Mamoli B, Austrian Immunoglobulin in Multiple Sclerosis Study Group. Randomised placebo-controlled trial of monthly intravenous immunoglobulin therapy in relapsing-remitting multiple sclerosis. Lancet 1997;349:589-93.

16. Plasma Exchange/Sandoglobulin Guillain-Barre Syndrome Trial Group. Randomized trial of plasma exchange, intravenous immunoglobulin, and combined treatments in Guillain-Barre syndrome. Lancet 1997;349:225-30.

17. van der Meche F, Schmitz P, Dutch Guillain-Barre Study Group. A randomized trial comparing intravenous immune globulin and plasma exchange in Guillain-Barre syndrome. N Engl J Med 1992;326:1123-9.

18. Canadian Pharmacists Association. Compendium of Pharmaceuticals and Specialties, 35th edn. Toronto: Webcom Limited, 2000.

19. Sibbald B. Does Canada face a crisis? US considers ending plasma exports. CMAJ 1998;158:1639-41.

20. Kress H, Scheidwig C, Schmidt H, Silber R. Reduced incidence of postoperative infection after intravenous administration of an immunoglobulin A- and immunoglobulin $\mathrm{M}$-enriched preparation in anergic patients undergoing cardiac surgery. Crit Care Med 1999;27:1281-7.

21. Douzinas E, Pitaridis M, Louris G, et al. Prevention of infection in multiple trauma patients by high-dose intravenous immunoglobulins. Crit Care Med 2000;28:8-15.

22. Baker S, O'Neill B, Haddon W, et al. The injury severity score: a method for describing patients with multiple injuries and evaluating emergency care. J Trauma 1974;14:187-96.

23. Mao P, Enrichens F, Olivero G, et al. Early administration of intravenous immunoglobulins in the prevention of surgical and post-traumatic sepsis: a double-blind randomized clinical trial. Surg Res Comm 1989;5:93-8.

24. Dominioni L, Dionigi R, Zanello M, et al. Effects of high-dose IgG on survival of surgical patients with sepsis scores of 20 or greater. Arch Surg 1991;126:236-40.

25. Knause W, Draper E, Wagner DP, Zimmerman JE. APACHE II: A severity of disease classification system. Crit Care Med 1985;13:818-29.

26. Dionigi R, Dominioni L, Jemos R, Cremaschi R, Bobbio-Pallavicini F Ballabio A. Sepsis score and complement factor B for monitoring severely septic surgical patients and for predicting their survival. Eur Surg Res 1985;17:269-80.

27. Dominioni L, Bianchi V, Imperatori A, Minoia G, Dionigi R. High-dose intravenous IgG for treatment of severe surgical infections. Dig Surg 1996;13:430-4.

28. Schedel I, Dreikhausen U, Nentwig B, et al. Treatment of Gramnegative septic shock with an immunoglobulin preparation: A prospective, randomized clinical trial. Crit Care Med 1991;19:1104-13.

29. Wortel C, Dellinger R. Treatment of Gram-negative septic shock with an immunoglobulin preparation: a prospective, randomized clinical trial. Crit Care Med 1993;21:163-5.

30. Grundmann R, Hornung M. Immunoglobulin therapy in patients with endotoxemia and post operative sepsis - a prospective randomized study. Prog Clin Biol Res 1988;272:339-49.

31. Wesoly C, Kipping N, Grundmann R. Immunoglobulin therapy of the postoperative sepsis. Z Exp Chir Transplant Kunstliche Organe 1990;2:213-6.

32. De Simone C, Delogu G, Corbetta G. Intravenous immunoglobulins in association with antibiotics: A therapeutic trial in septic intensive care unit patients. Crit Care Med 1988;16:23-6.

33. Just $\mathrm{H}$, Metzger M, Vogel W, Pelka R. Effect of adjuvant immunoglobulin therapy on infections in patients in a surgical intensive care unit. Results of a randomized controlled study. Klin Wochenschr 1986;64:245-56.

34. Werdan K. Supplemental immune globulins in sepsis. Clin Chem Lab Med 1999;37:341-9.

35. Pilz G, Fateh-Moghadan S, Viell B, et al. Supplemental immunoglobulin therapy in sepsis and septic shock - comparison of mortality under treatment with polyvalent IV immunoglobulin versus placebo. Protocol of a multicenter, randomized, prospective, double-blind trial. Theor Surg 1993;8:61-83.

36. Werdan K, Pilz G. Supplemental immune globulins in sepsis: a critical appraisal. Clin Exp Immunol 1996;104(Suppl 1):83-90.

37. Laupland K, Davies H. Epidemiology, etiology, and management of Kawasaki Disease: state of the art. Pediatr Cardiol 1999;20:177-83.

38. Sibbald W, Vincent J-L. Roundtable conference on clinical trials for the treatment of sepsis. Chest 1995;107:522-7.

39. Kaul R, McGeer A, Norrby-Teglund A, et al. Intravenous immunoglobulin therapy for streptococcal toxic shock syndrome a comparative observational study. Clin Infect Dis 1999;28:800-7. 


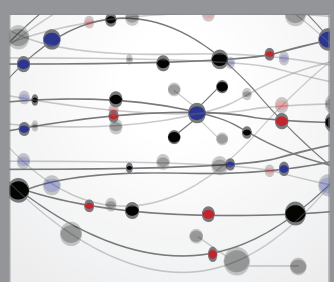

The Scientific World Journal
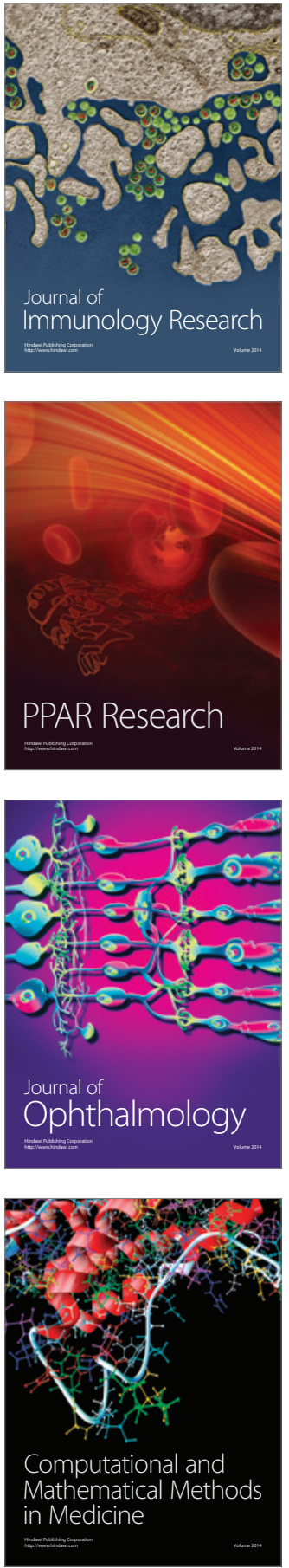

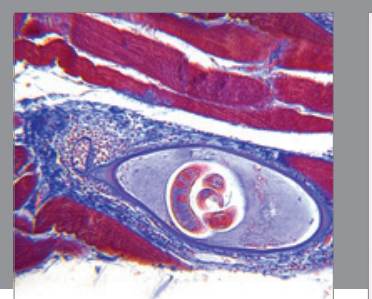

Gastroenterology Research and Practice

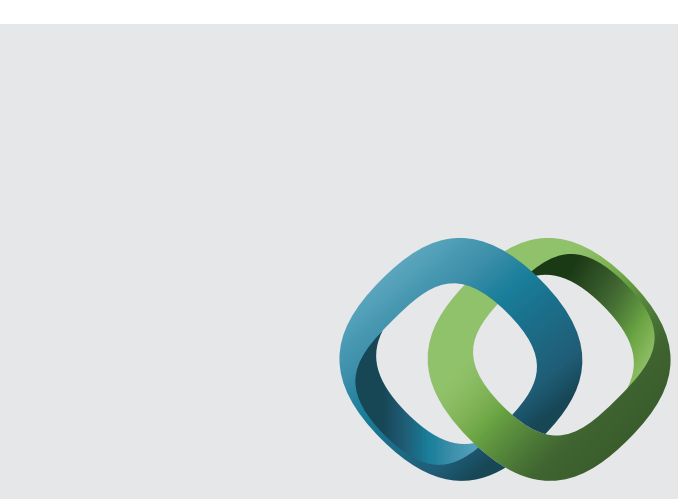

\section{Hindawi}

Submit your manuscripts at

http://www.hindawi.com
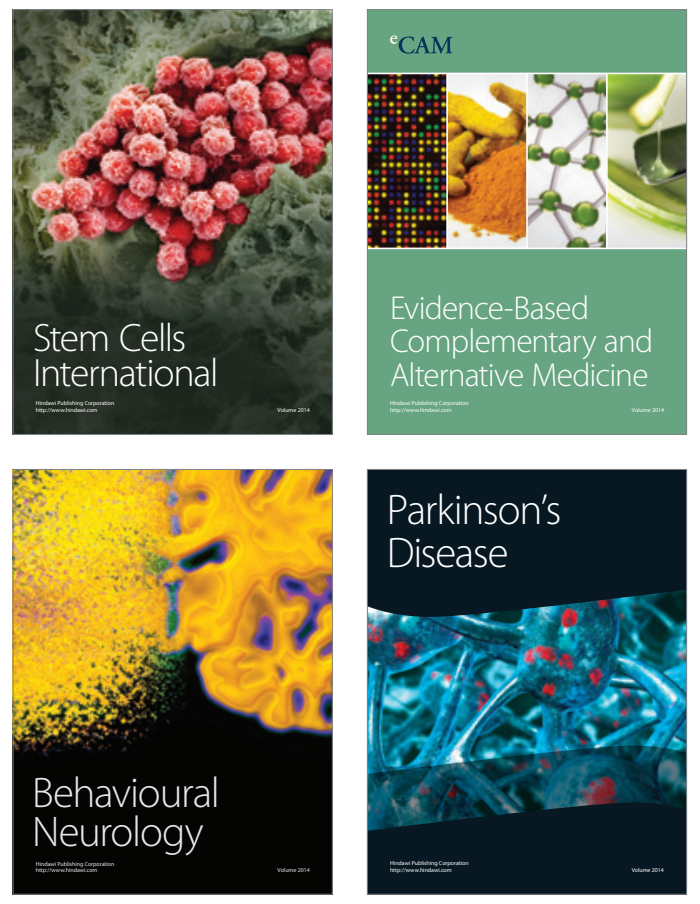
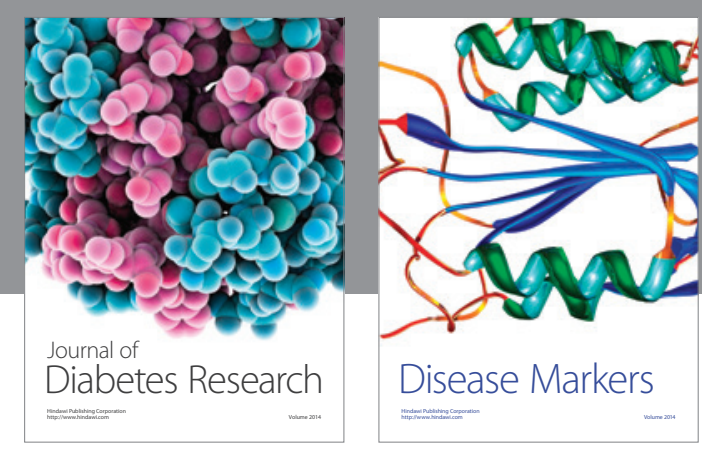

Disease Markers
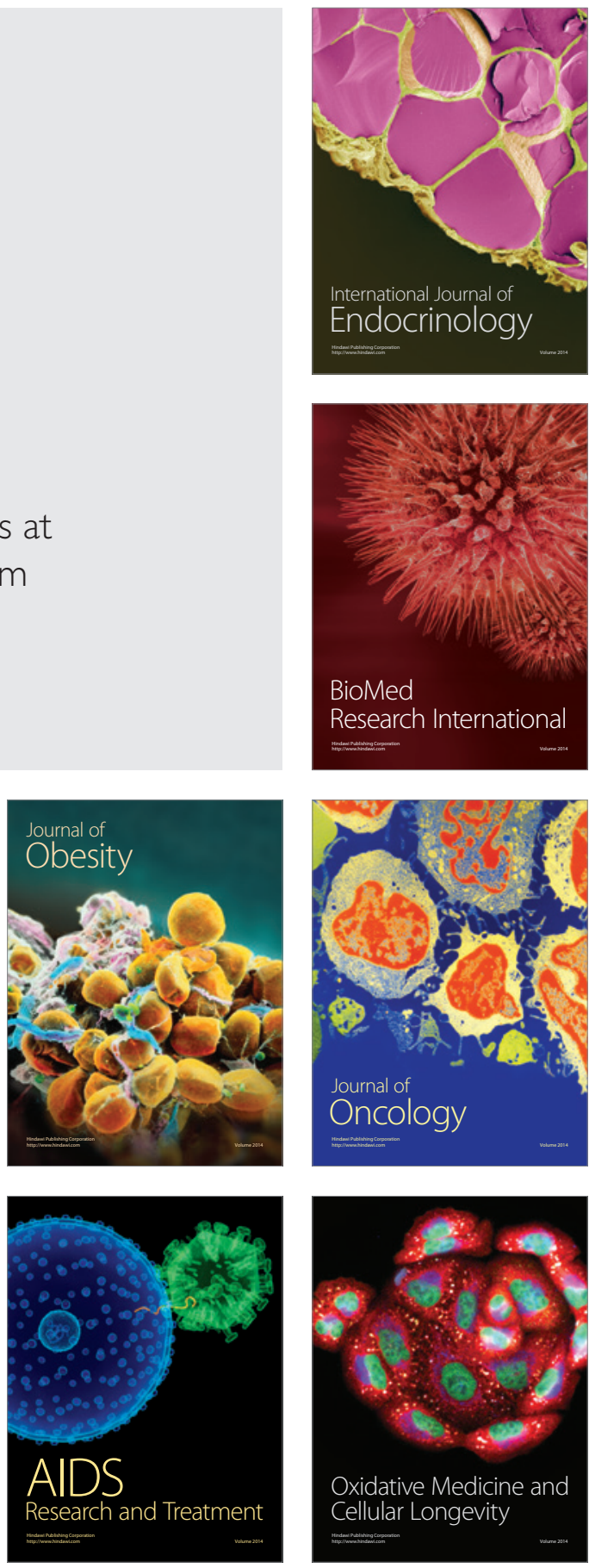